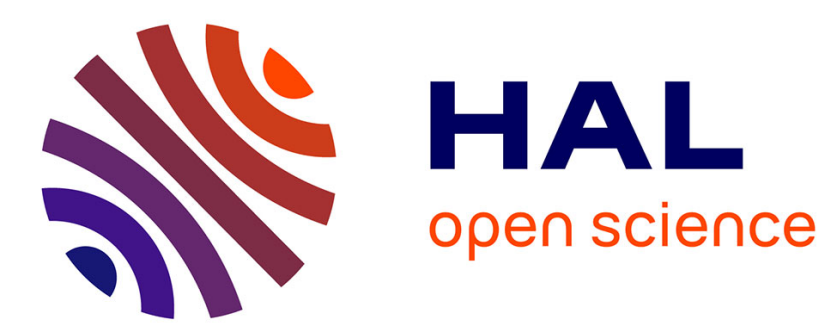

\title{
MÖSSBAUER EFFECT OBSERVATION OF DIVALENT GADOLINIUM
}

\author{
H. Buskes, J. Cashion
}

\section{To cite this version:}

H. Buskes, J. Cashion. MÖSSBAUER EFFECT OBSERVATION OF DIVALENT GADOLINIUM. Journal de Physique Colloques, 1974, 35 (C6), pp.C6-221-C6-223. 10.1051/jphyscol:1974626 . jpa00215783

\section{HAL Id: jpa-00215783 \\ https://hal.science/jpa-00215783}

Submitted on 1 Jan 1974

HAL is a multi-disciplinary open access archive for the deposit and dissemination of scientific research documents, whether they are published or not. The documents may come from teaching and research institutions in France or abroad, or from public or private research centers.
L'archive ouverte pluridisciplinaire HAL, est destinée au dépôt et à la diffusion de documents scientifiques de niveau recherche, publiés ou non, émanant des établissements d'enseignement et de recherche français ou étrangers, des laboratoires publics ou privés. 


\title{
MÖSSBAUER EFFECT OBSERVATION OF DIVALENT GADOLINIUM
}

\author{
H. A. BUSKES and J. D. CASHION $\left({ }^{*}\right)$
}

Department of Physics, Monash University, Clayton, Victoria, 3168, Australia

\begin{abstract}
Résumé. - L'absorption résonnante des rayons $\gamma$ de $86,5 \mathrm{keV}$ de ${ }^{155} \mathrm{Gd}$ a été utilisée pour détecter le gadolinium divalent dans $\mathrm{CaF}_{2}: \mathrm{Gd}$. Le déplacement isomérique mesuré entre $\mathrm{Gd}^{2+}$ et $\mathrm{Gd}^{3+}$ est $+(0,35+0,09) \mathrm{mm} \mathrm{s}^{-1}$, ce qui confirme la structure électronique $4 \mathrm{f}^{7} 5 \mathrm{~d}^{1} \mathrm{de} \mathrm{Gd}^{2+}$. On déduit la valeur $\Delta\left\langle r^{2}\right\rangle=-(8,2 \pm 2,1) \times 10^{-3} \mathrm{fm}^{2}$ pour la transition de $86,5 \mathrm{keV}$. Les éclatements mesurés pour le gadolinium dans l'état divalent sont beaucoup plus élevés que pour le gadolinium trivalent.
\end{abstract}

\begin{abstract}
Resonant absorption of the $86.5 \mathrm{keV}$ gamma rays from $155 \mathrm{Gd}$ has been used to detect divalent gadolinium in $\mathrm{CaF}_{2}: \mathrm{Gd}$. The isomer shift between $\mathrm{Gd}^{2+}$ and $\mathrm{Gd}^{3+}$ was measured to be $+(0.35 \pm 0.09) \mathrm{mm} \mathrm{s}^{-1}$ confirming that the electron configuration of $\mathrm{Gd}^{2+}$ is $4 \mathrm{f}^{7} 5 \mathrm{~d}^{1}$. The value of $\Delta\left\langle r^{2}\right\rangle$ for the $86.5 \mathrm{keV}$ transition was deduced to be $-(8.2 \pm 2.1) \times 10^{-3} \mathrm{fm}^{2}$. The measured splittings for gadolinium in the divalent state were found to be considerably larger than for trivalent gadolinium.
\end{abstract}

1. Introduction. - The isomer shift observed in a Mössbauer experiment is the electric monopole interaction between the nucleus and the electrons. The parameters involved in its interpretation are the change in the mean-square nuclear charge radius, $\Delta\left\langle r^{2}\right\rangle$, between the ground and excited states and the difference in the electron density at the nucleus in the source and absorber $\Delta|\psi(0)|^{2}$. The determination of $\Delta\left\langle r^{2}\right\rangle$ is usually carried out by measuring the isomer shift between ionic compounds of two different valence states of the nuclide concerned and then using a self-consistent-field calculation to estimate $|\psi(0)|^{2}$ for the two free ion configurations.

However gadolinium is probably the most difficult of the rare earths to obtain in a valence state other than the usual trivalent one and this has hampered determinations of $\Delta\left\langle r^{2}\right\rangle$ values for gadolinium isotopes. In order to try and improve the current estimate of $\Delta\left\langle r^{2}\right\rangle$ for the principal Mössbauer transition in gadolinium, the $86.5 \mathrm{keV}$ gamma ray in ${ }^{155} \mathrm{Gd}$, and determine it on a consistent basis with the other rare earths, we have attempted to produce divalent gadolinium. Another factor of interest in the experiment was the likelihood that the electron configuration of $\mathrm{Gd}^{2+}$ would be $4 \mathrm{f}^{7} 5 \mathrm{~d}^{1}$ instead of the conventional $4 f^{8}$, although this unfortunately reduces the size of the isomer shift and hence lowers the accuracy of the $\Delta\left\langle r^{2}\right\rangle$ determination.

(*) At present on leave at Physik Department E15, Technische Universität München, D8046 Garching bei München.
2. Sample preparation. $-\mathrm{CaF}_{2}$ was chosen as the host since it is a light cubic material containing a cation of the correct valency and ionic radius and has already been used sucessfully for producing divalent rare earths for optical and Mössbauer experiments. Samples were prepared from $\mathrm{CaF}_{2}$ and $\mathrm{GdF}_{3}$ by mechanically mixing the correct proportions of finely ground powder, pressing and then sintering at $1300^{\circ} \mathrm{C}$ for $24 \mathrm{~h}$. Samples were prepared using 11 at. $\%$ and 1 at. $\% \mathrm{Gd}$ and cut into thicknesses of $8 \mathrm{~mm}$ and $15 \mathrm{~mm}$ respectively.

Three methods were used to try and enhance the ratio of $\mathrm{Gd}^{2+} / \mathrm{Gd}^{3+}$. The first two methods were solid state electrolysis and irradiation in the direct beam of a $2 \mathrm{~kW}$ x-ray set for $24 \mathrm{~h}$, neither of which produced any detectable change in the Mössbauer absorption spectrum. The third method [1] was to heat the samples in calcium vapour for $3 \mathrm{~h}$ at approximately $600^{\circ} \mathrm{C}$ and the results of this will be described in the next section.

The single line source used for all experiments was SmPd containing approximately 4 at. $\% \mathrm{Sm}$. The sample was irradiated for 7 days at $3 \times 10^{13}$ neutrons $\mathrm{cm}^{-2} \mathrm{~s}^{-1}$ to produce a $1 \mathrm{mCi}$ source via the ${ }^{154} \mathrm{Sm}(\mathrm{n}, \gamma)$ reaction.

3. Results. - All measurements were taken using a conventional constant acceleration drive mounted vertically in a helium cryostat with both the source and absorber at $4.2 \mathrm{~K}$. The spectra were recorded on a 400 channel analyzer.

Measurements on the samples containing $11 \% \mathrm{Gd}$ 
in $\mathrm{CaF}_{2}$ all gave symmetrical spectra. However considerable differences were observed between samples and two spectra obtained are shown in figure $1 a$ and $b$. We

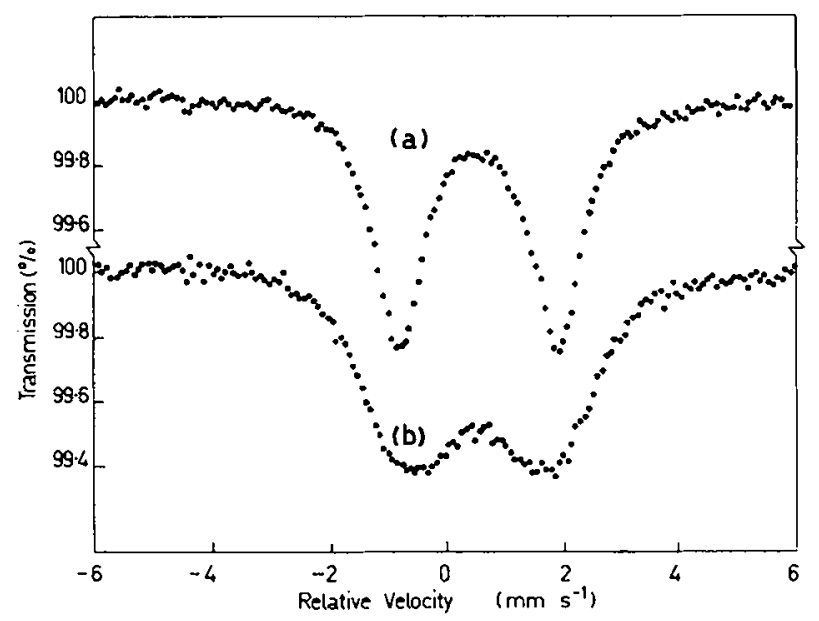

FIG. 1. - Mössbauer absorption spectra of two different samples of $11 \%$ trivalent gadolinium in calcium fluoride.

were unable to determine systematically the causes for such a large change in the spectra which are apparently due to small changes in the chemical preparation.

All the spectra can be explained by quadrupole splitting alone and no evidence was found for a site of cubic symmetry at the centre of the spectrum. Fourteen different lines were observed with the parameters being given in Table I. We would tentatively assign the

\section{TABle I}

$\mathrm{Gd}^{3+}$ in $\mathrm{CaF}_{2}$

\begin{tabular}{ccc} 
Line Positions & $\begin{array}{c}\text { Isomer } \\
\text { Shift }\end{array}$ & Splitting \\
$+0.13(10)+1.03(10)$ & $\overline{0.58}$ & $0 . \overline{9}$ \\
$-0.27(10)+1.43(10)$ & 0.58 & 1.7 \\
$-0.77(1)+1.95(1)$ & 0.59 & 2.72 \\
$-1.31(5)+2.47(5)$ & 0,58 & 3.78 \\
$-1.55(10)+2.71(10)$ & 0.58 & 4.3 \\
$-2.03(10)+3.03(10)$ & 0.50 & 5.1 \\
$-2.55(10)+3.60(10)$ & 0.52 & 6.1 \\
$+0.58(3)$ & 0.58 & $0\left(^{* *}\right)$ \\
\multicolumn{5}{c}{ Gd $^{2+}$} & in $\mathrm{CaF}_{2}$ & \\
Line Positions & Isomer & Shift \\
$+0.93(7)$ & 0.93 & Splitting \\
$-0.97(3)+2.80(3)$ & 0.92 & 0 \\
$-2.77(10)+4.63(10)$ & 0.93 & 7.77 \\
$-4.60(10)+6.46(10)$ & 0.93 & 11.1 \\
$-6.50(15)+8.50(15)$ & 1.0 & 15.0 \\
$-8.1(2)+9.9(2)$ & 0.9 & 18.0
\end{tabular}

All measurements are in units of $\mathrm{mm} \mathrm{s}^{-1}$.

The figure in brackets indicates the error in the last digit.

$\left({ }^{* *}\right)$ See text. dominant spectrum in figure $1 a$ with a splitting of $(2.72 \pm 0.02) \mathrm{mm} \mathrm{s}^{-1}$ to $\mathrm{a} \mathrm{Gd}^{3+}$ ion accompanied by a charge compensating $\mathrm{F}^{-}$at the next vacant interstitial site in the simple cubic fluorine sublattice as observed by Baker et al. [2].

From Table I we would estimate that the isomer shift of $\mathrm{CaF}_{2}: \mathrm{Gd}^{3+}$ is $+(0.58 \pm 0.02) \mathrm{mm} \mathrm{s}^{-1}$ with respect to our SmPd source. This can be compared with the isomer shift for $\mathrm{GdF}_{3}$ and $\mathrm{Gd}_{2}\left(\mathrm{SO}_{4}\right)_{3}$ of 0.66 $0.67 \mathrm{~mm} \mathrm{~s}^{-1}$ [3] and the typical range of $\mathrm{Gd}^{3+}$ isomer shifts in insulators of $0.45-0.67 \mathrm{~mm} \mathrm{~s}^{-1}$.

As mentioned in section 2, $\mathrm{x}$-irradiation and solid state electrolysis did not produce any discernable change in the spectrum. However heating in calcium vapour produced a small peak at $+(0.95 \pm 0.08) \mathrm{mm} \mathrm{s}^{-1}$ barely observable against the dominant $\mathrm{Gd}^{3+}$ spectra. It is to be remembered that in trying to observe this peak there is also a contribution from the photoelectric effect interference term which tends to make the central region asymmetrical in the opposite direction.

We interpret this single peak as being due to a $\mathrm{Gd}^{2+}$ ion which is now in a site of cubic symmetry due to the diffusing away of the charge compensating fluorine interstitial. However it seemed reasonable to assume that in the cases where gadolinium atoms were close together they would be more stable and hence resist reduction to $\mathrm{Gd}^{2+}$. Further experiments were therefore carried out on samples of $1 \% \mathrm{Gd}$ in $\mathrm{CaF}_{2}$, again heated in calcium vapour.

The spectrum produced was now definitely asymmetrical with an appreciable contribution from both divalent and trivalent gadolinium up to a maximum of approximately $20 \%$ divalent. One of these spectra is shown in figure 2 and again slightly different spectra were produced by different samples. Separation of these spectra was difficult but was achieved mainly

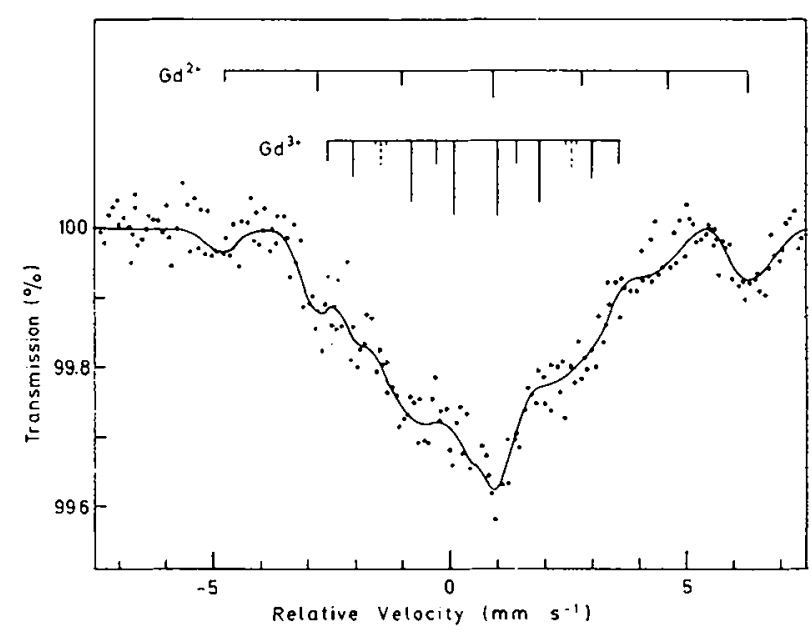

FIG. 2. - Mössbauer absorption spectrum of $1 \%$ gadolinium in calcium fluoride containing both divalent and trivalent gadolinium. The line intensity shown dotted could not be resolved in this spectrum between the two proper line positions shown on either side. The asymmetry in the outer peaks is due to nonlinearity near the drive turnaround. 
by subtraction of spectra taken before and after calcium treatment, helped by the fact that different samples emphasized different lines. However all the spectra were fitted to the same lines and these parameters are also given in Table I. The mean isomer shift for $\mathrm{CaF}_{2}: \mathrm{Gd}^{2+}$ was estimated to be $+(0.93 \pm 0.07) \mathrm{mm} \mathrm{s}^{-1}$ with respect to SmPd.

Heating the sample in calcium vapour also sometimes resulted in the production of a $\mathrm{Gd}^{3+}$ spectrum which is unsplit or at most has a quadrupole splitting of less than a linewidth $\left(0.8 \mathrm{~mm} \mathrm{~s}^{-1}\right)$. If it is really an unsplit line due to $\mathrm{Gd}^{3+}$ in a site of cubic symmetry then the probable mechanism would seem to be reduction to $\mathrm{Gd}^{2+}$ and the subsequent diffusing away of the charge compensating $\mathrm{F}^{-}$ion during the calcium treatment, followed by a later reversion to $\mathrm{Gd}^{3+}$. This is supported by our frequent observation that the spectrum appeared to change during running (although such conclusions are easy to draw with inadequate statistics) and subsequent running produced a different spectrum. However with a typical running time of 1-2 weeks there does seem a possibility that radiation-induced defects were in fact annealling out the divalent spectrum.

4. Discussion. - The current literature value (4) of $\Delta\left\langle r^{2}\right\rangle$ for ${ }^{155} \mathrm{Gd}$ is $-(6-10) \times 10^{-3} \mathrm{fm}^{2}$ and this would indicate an isomer shift of

$$
\begin{aligned}
& \delta\left(4 \mathrm{f}^{8}-4 \mathrm{f}^{7}\right) \approx 1.4 \mathrm{~mm} \mathrm{~s}^{-1} \\
& \delta\left(4 \mathrm{f}^{7} 5 \mathrm{~d}^{1}-4 \mathrm{f}^{7}\right) \approx 0.3 \mathrm{~mm} \mathrm{~s}^{-1}
\end{aligned}
$$

for the two possible configurations of divalent gado- linium. It is therefore clear that the $\mathrm{Gd}^{2+}$ is in the configuration $4 \mathrm{f}^{7} 5 \mathrm{~d}^{1}$ as suggested by McClure and Kiss [5] from their optical experiments.

As part of a detailed comparison of isomer shifts in different rare earths [6] we have carried out relativistic Hartree-Fock calculations of $|\psi(0)|^{2}$ for these free ion configurations. Using these results in conjunction with the measurement

$$
\begin{aligned}
\delta\left(\mathrm{CaF}_{2}: \mathrm{Gd}^{2+}\right)-\delta\left(\mathrm{CaF}_{2}: \mathrm{Gd}^{3+}\right)= & \\
& =+(0.35 \pm 0.09) \mathrm{mm} \mathrm{s}^{-1}
\end{aligned}
$$

gives us the value $\left.\Delta<r^{2}\right\rangle=-(8.2 \pm 2.1) \times 10^{-3} \mathrm{fm}^{2}$. This is in good agreement with the value

$$
-8.7 \times 10^{-3} \mathrm{fm}^{2}
$$

obtained in [6] from other measurements.

The measured hyperfine splittings of the divalent spectra are a factor of four larger than those for gadolinium in the trivalent state. The largest quadrupole splitting previously reported is $5.4 \mathrm{~mm} \mathrm{~s}^{-1}$ in monoclinic $\mathrm{Gd}_{2} \mathrm{O}_{3}$ [3]. Larger hyperfine splittings for $\mathrm{Gd}^{2+}$ are to be expected because the outer electronic shell no longer possesses the symmetry of the half-filled $4 \mathrm{f}^{7}$ configuration.

Acknowledgments. - We are indebted to A. Vas for his assistance in preparing the specimens and to M. A. Coulthard for the relativistic Hartree-Fock calculations. This work was supported by the Australian Research Grants Committee and the Australian Institute for Nuclear Science and Engineering.

\section{References}

[1] Kiss, Z. J. and Yocum, P. N., J. Chem. Phys. 41 (1964) 1511.

[2] Baker, J. M., Davies, E. R. and Hurrell, J. P., Proc. $R$. Soc. (Lond.) A 308 (1968) 403.

[3] Cashion, J. D., Prowse, D. B. and Vas, A., J. Phys. C: Solid State Physics 6 (1973) 2611.

[4] Shenoy, G. K. and Kalvius, G. M., Hyperfine Interactions in Excited Nuclei, Vol. 4, eds G. Goldring and R. Kalish (Gordon and Breach, New York) 1971, 1201.

[5] MCClure, D. S. and Kiss, Z. J., J. Chem. Phys. 39 (1963) 3251 .

[6] Cashion, J. D., Coulthard, M. A. and Prowse, D. B., J. Phys. C: (Solid State Physics) 7 (1974) 3620 and to be published. 